\title{
ضد العولمة وحرية التجارة، من يفوز؟
}

بقلم رئيس التحرير

لقد اعتقد الاقتصاديون لأمد طويل، أن مكاسب التجارة بين الدول (وتتشمل أسعاراً أقل

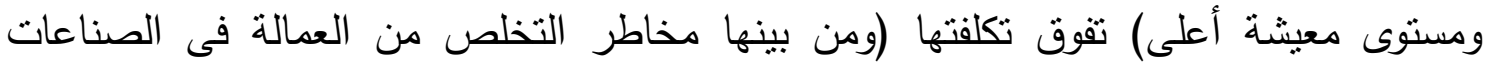

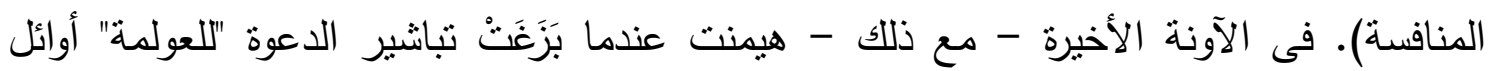

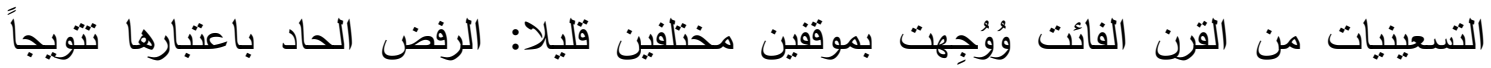

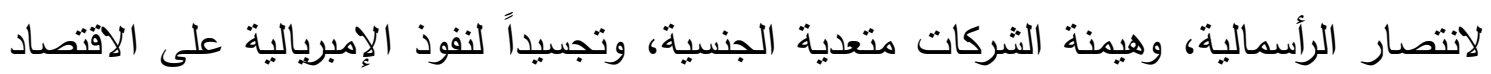

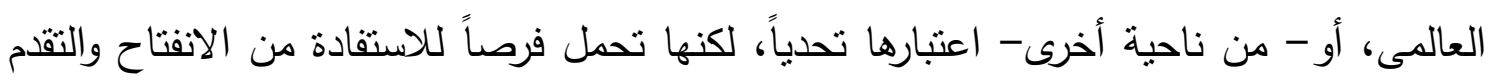

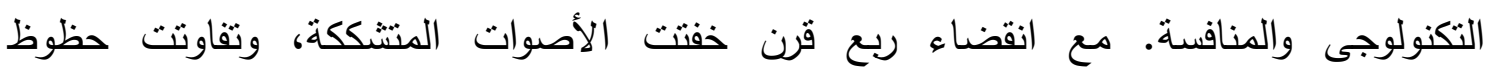

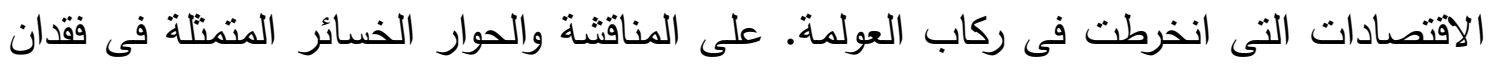

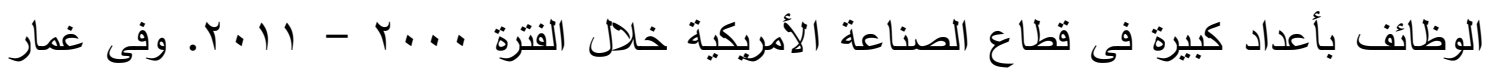

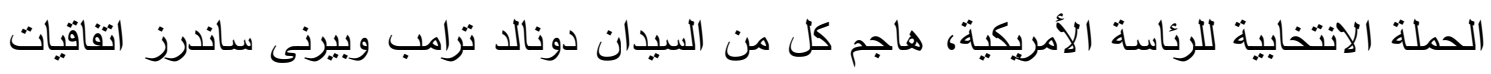

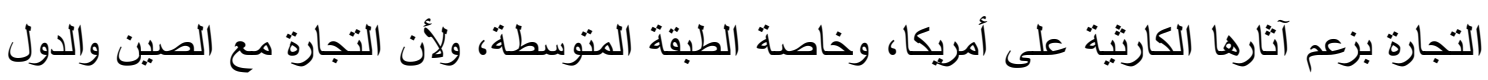

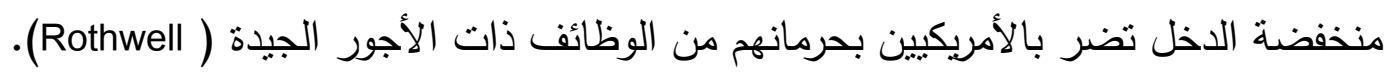

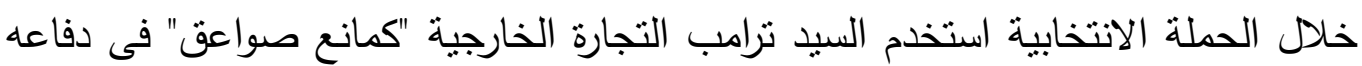

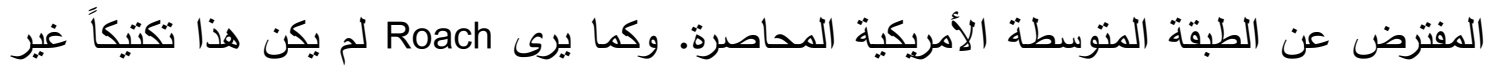

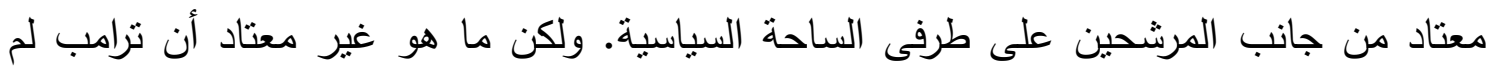

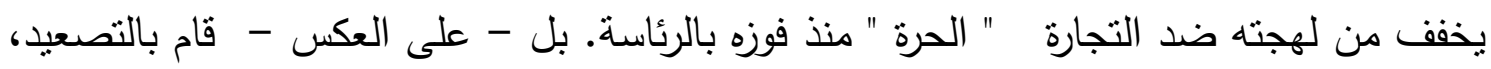

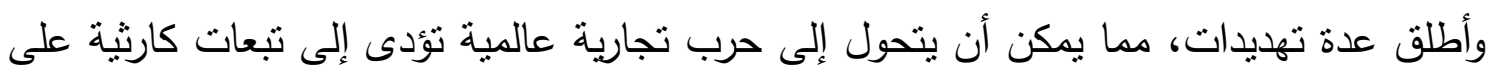




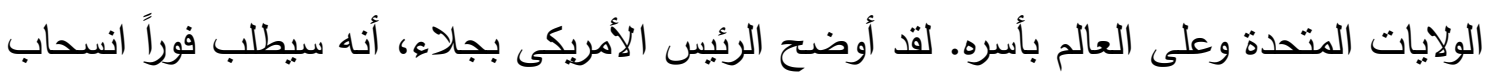

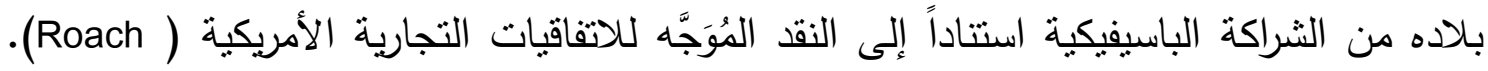

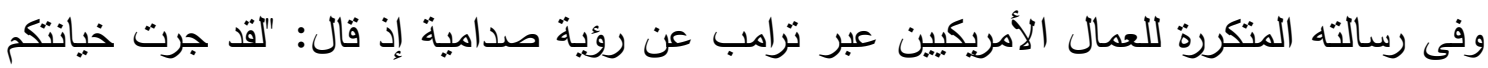

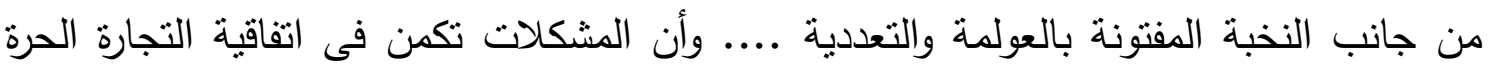

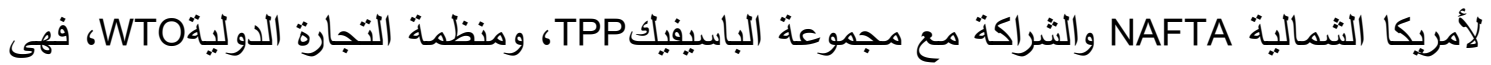

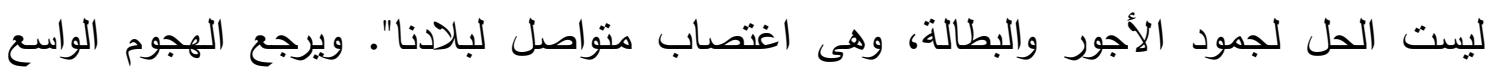

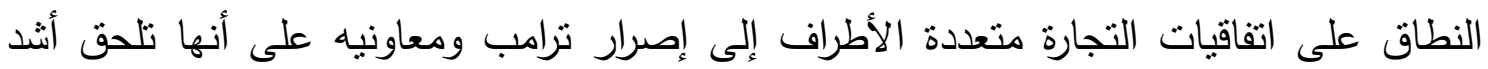

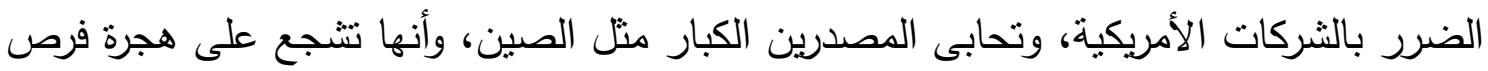
العمل إلى دول أخرى.Kucik)

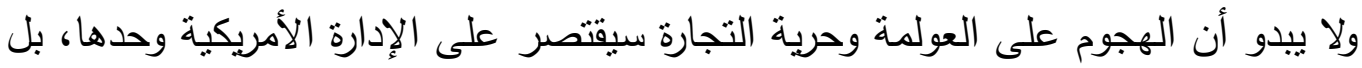

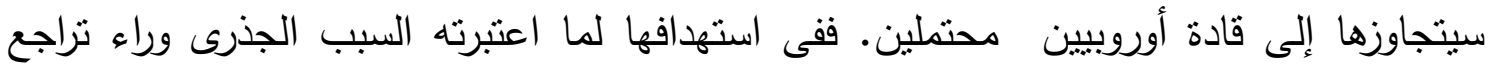
فرنسا، أكدت المرشحة للرئاسة الفرنسية Marine Le Pen أنها العولمة الاقتصادية. فقط من خلال

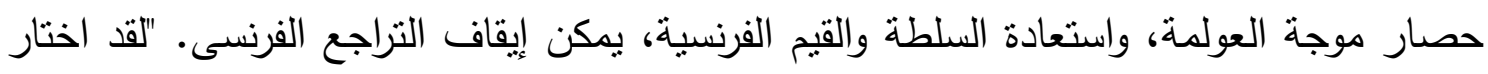

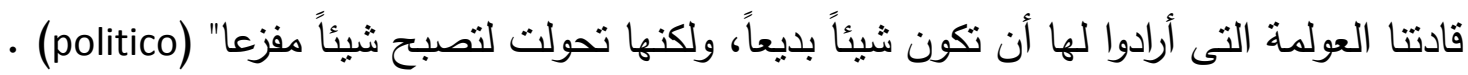

قد يرى البعض أنه فيما وراء الفوضى والضجيج الذى تحدثه خطب الرئيس الأمريكى

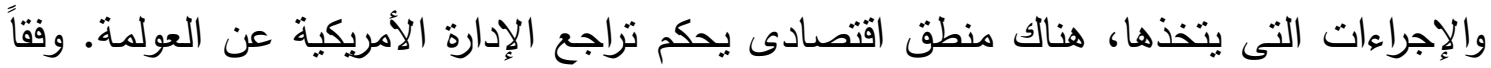

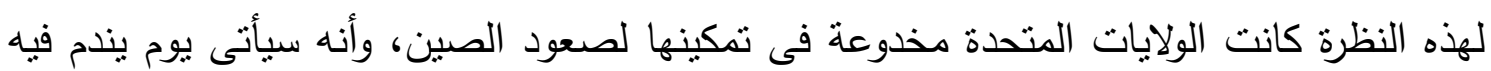

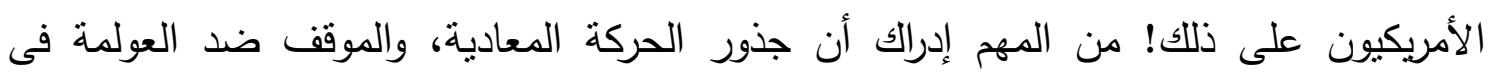

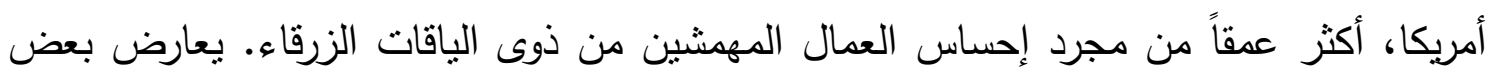

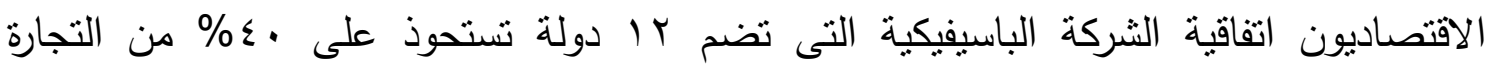

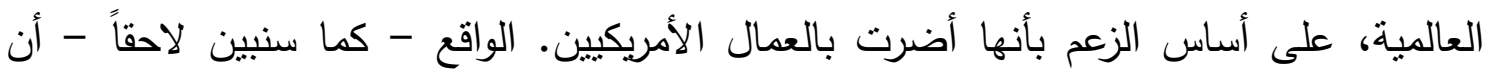
إسقاط الاتفاقية يفتح الباب أمام الصين للهيمنة الاقتصادية عبر الباسيفيك ( Rogoff). 


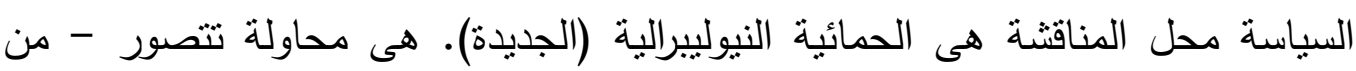

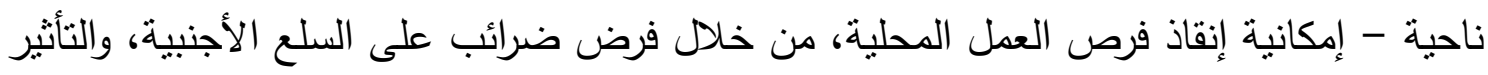

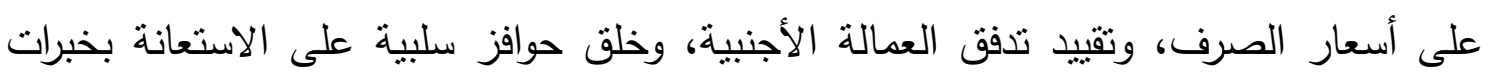

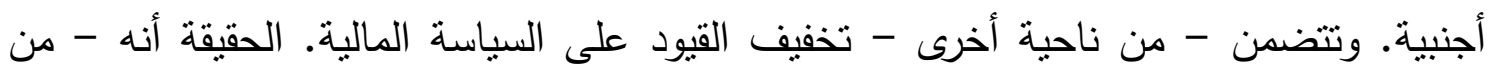
وجهة نظر البعض - ليس هذا هو السبيل لمساعدة الطبقة العاملة. العوامل الاقتصادية وراء

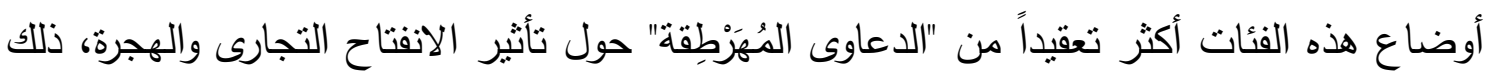
أن التحدى الرئيسى يكمن فى التطور التكنولوجى والإنتاجية ( Basu).

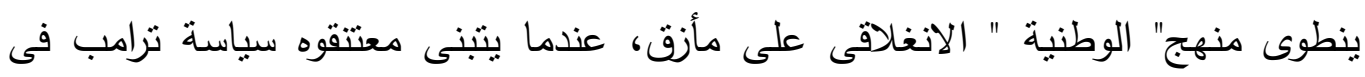

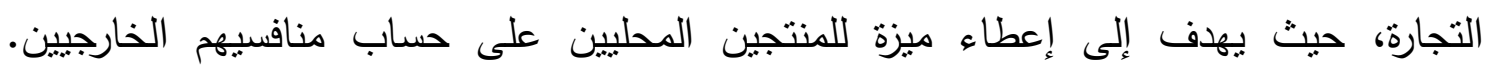

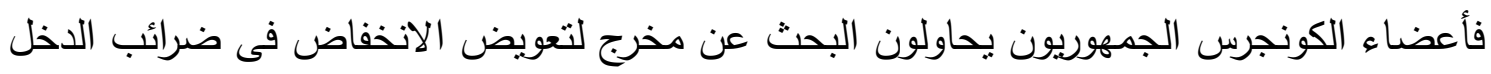

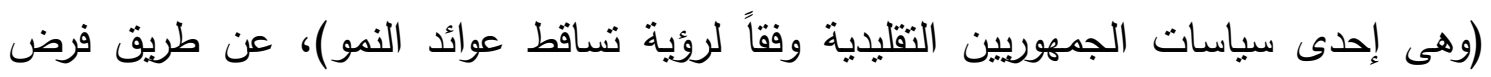

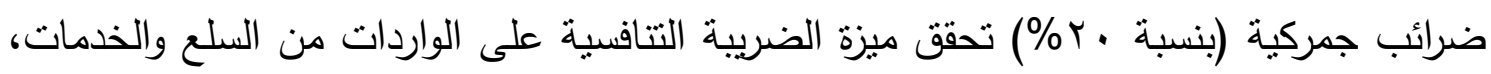

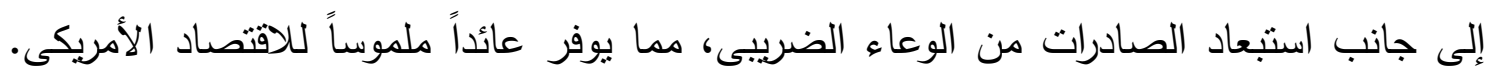

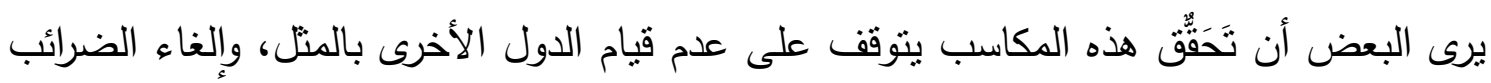
على دخل الثركات المنتجة للصادرات (keyu).

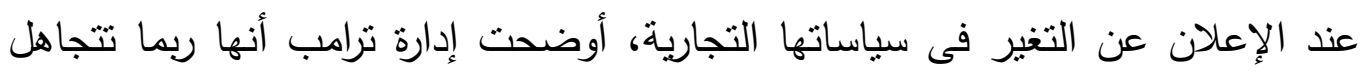

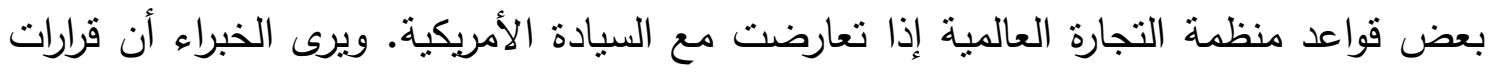

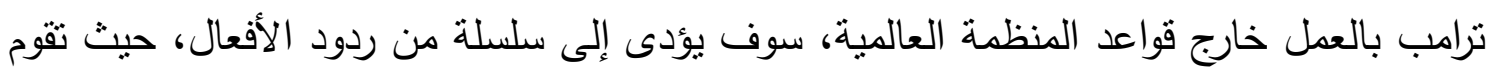

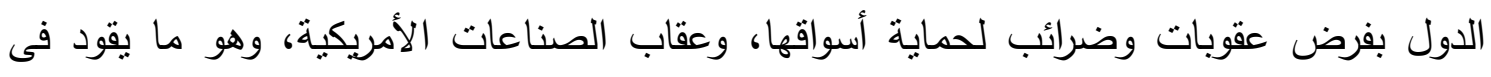

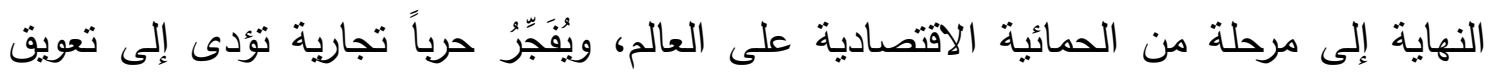
النشاط والنمو الاقتصادى العالمى(Paletta ). 
ينطلق الانغلاقيون (المتعصبون وطنباً) فى الولايات المتحدة وأوربا من الزعم بأن العولمة

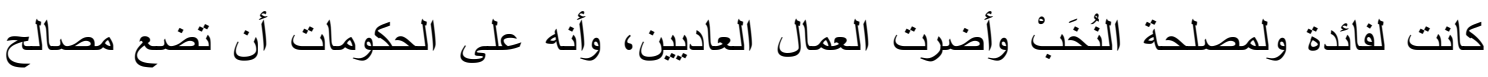

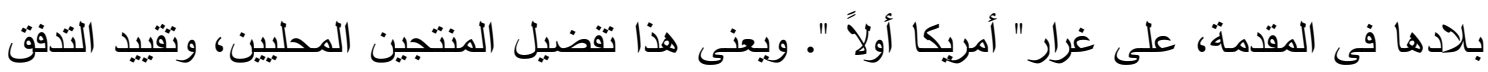

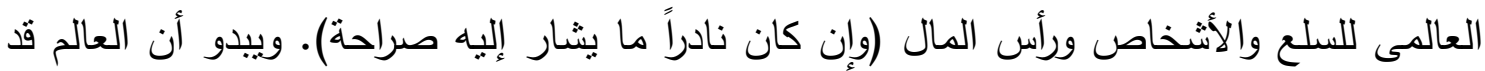

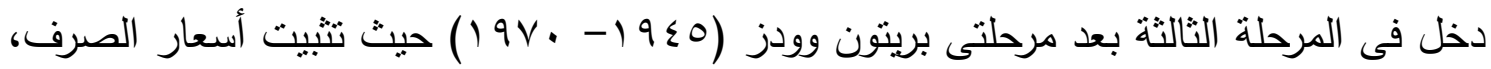

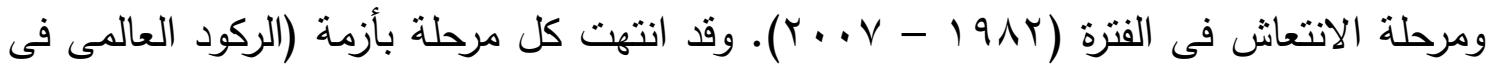

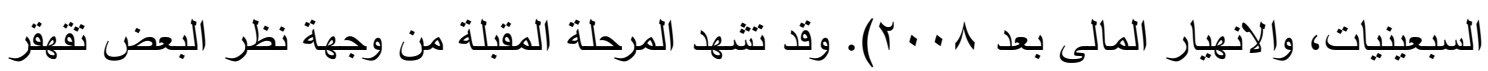

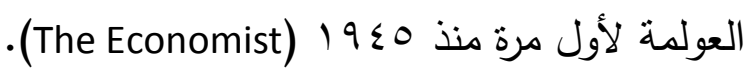

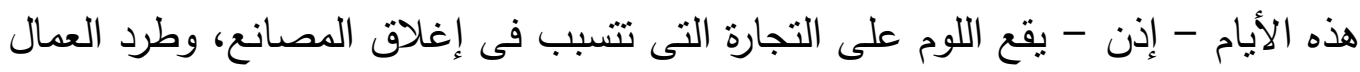

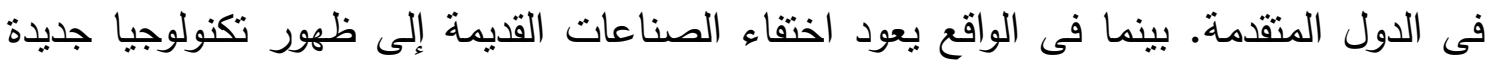

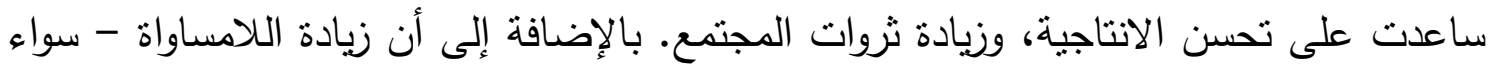

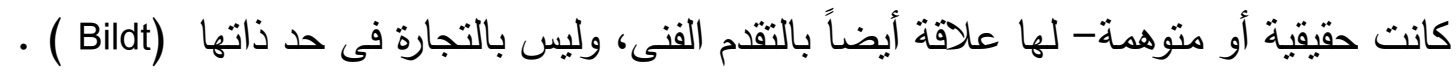

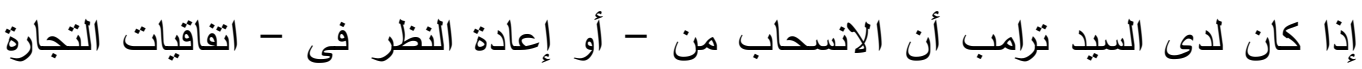

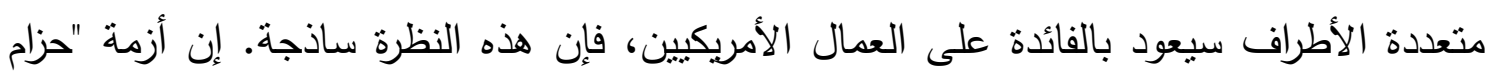

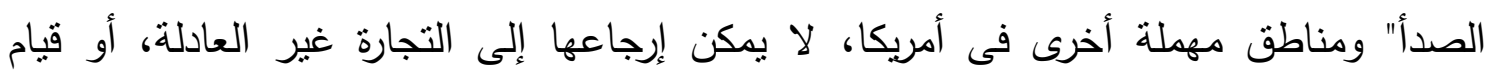

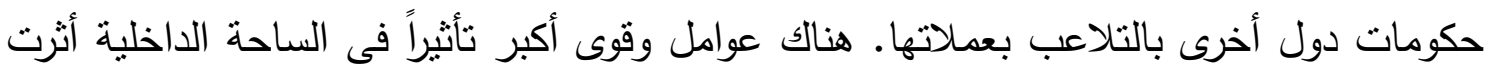

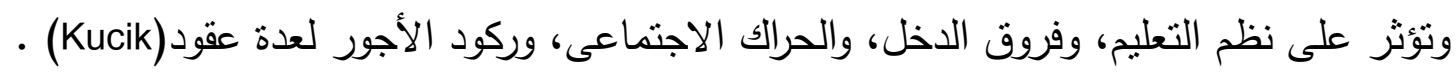

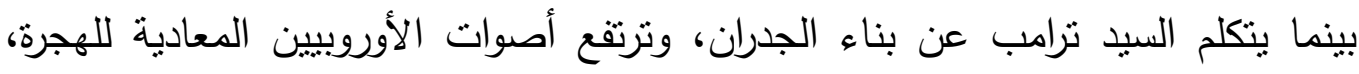

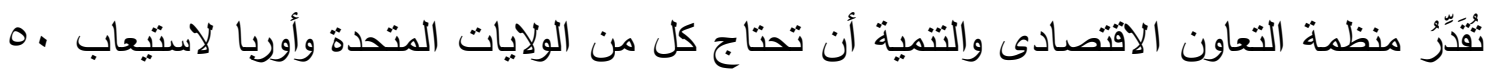

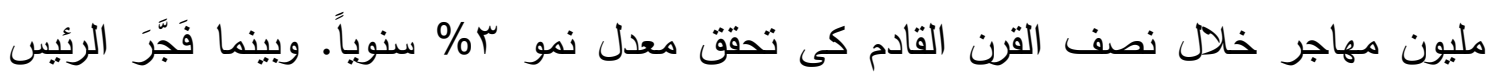

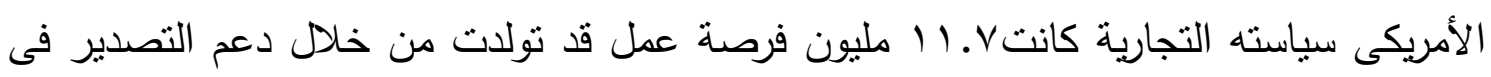

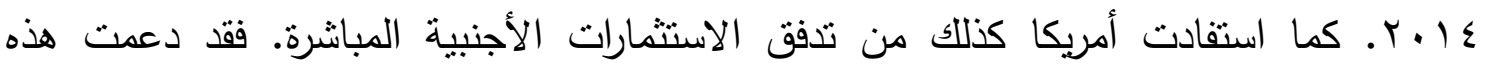

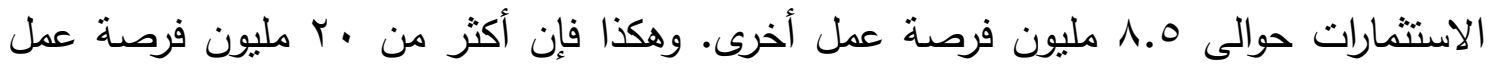

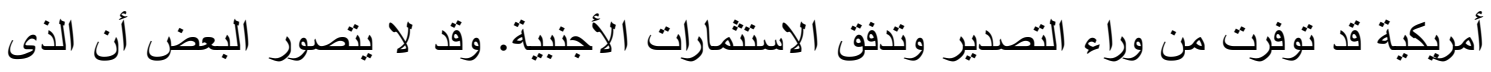


سجل السبق فى الاستثمار فى الاقتصاد الأمريكى هى الصين (أكبر شريك تجارى لأمريكا) التى

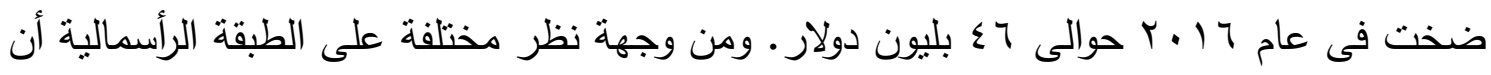

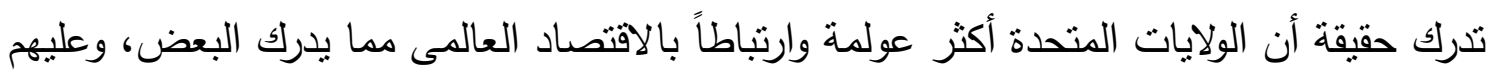

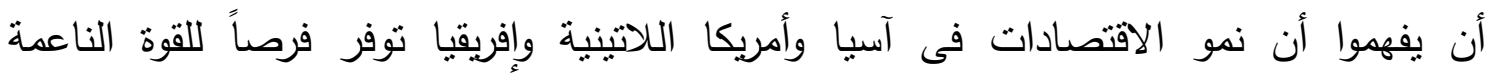
للابلوماسية الأمريكية، بل وتَعِدُ بفرص نمو للاقتصاد الأمريكى ذاته (Molavi) ل

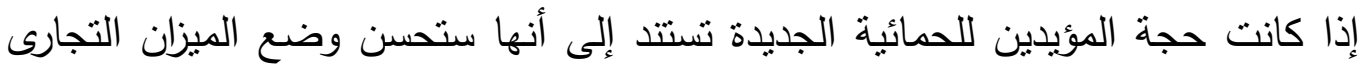

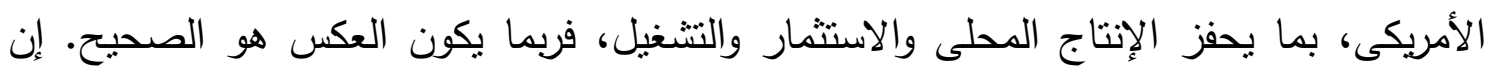

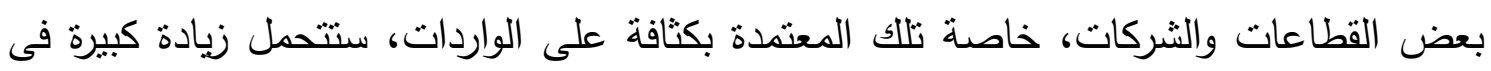

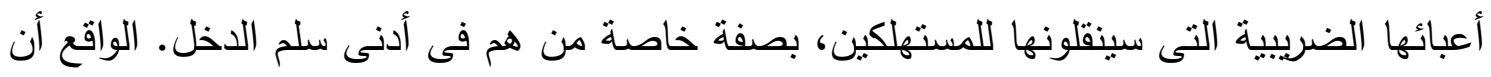

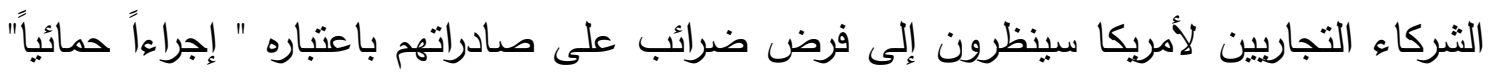

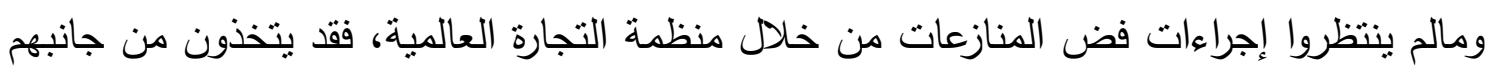
إجراءات إنتقامية، وسنكون الحرب التجارية التى لا يحتاجها الاقتصاد العالمى بأية حال (keyu).

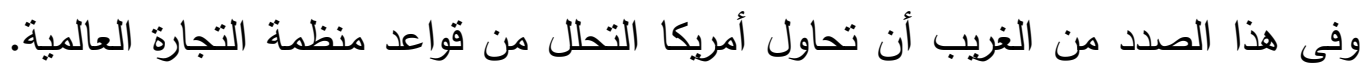

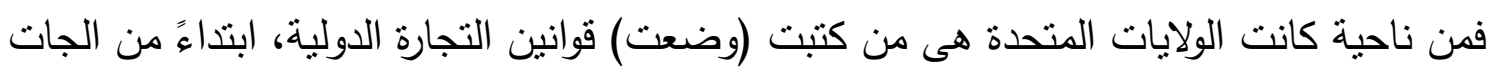

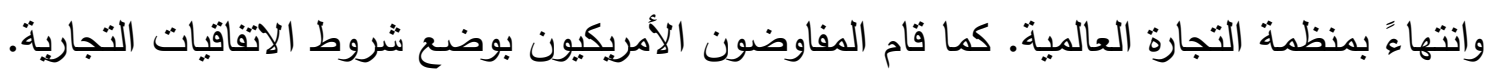

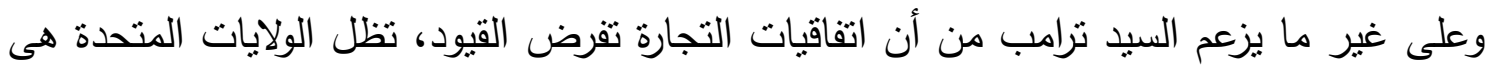

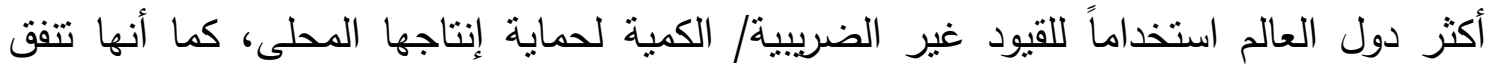

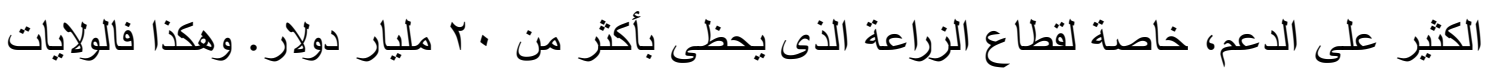

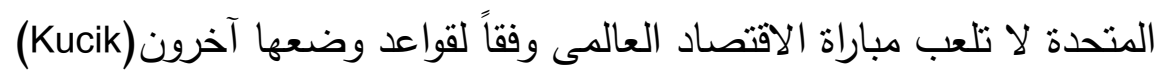

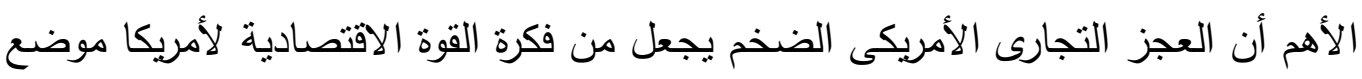

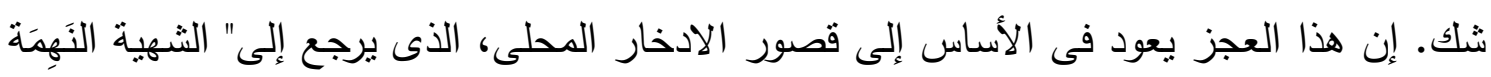

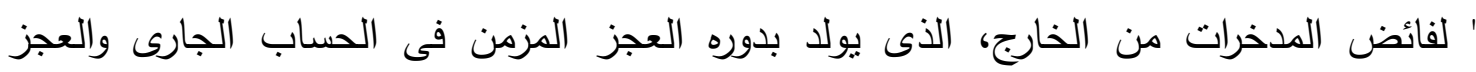

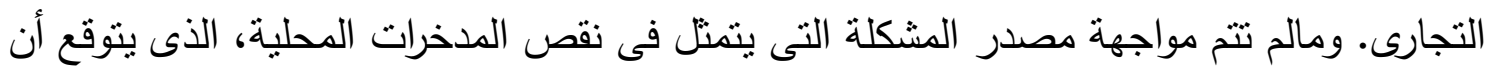

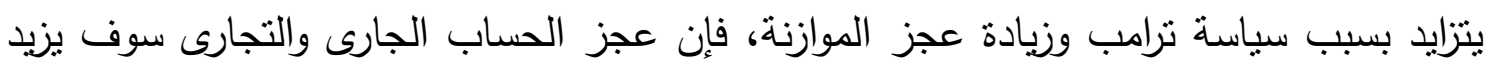


أيضاً. هناك ارتباط قوى بين الاختلال (عدم التوازن) فى الاقتصاد العالمى، والاختلال فى الإنى الاقتصاد المحلى، الذى يعود غالباً إلى سوء توزيع الدخل. ويثور اهتمام السياسات الماكرو اقتصادية - فى الحالين - نتيجة وجود زيادة مستمرة فى المدخرات المرغوبة عن الاستثمارات المتوقعة. وكما بشير Kemal Dervis فإن استعادة التوازن للاقتصاد العالمى، بتطلب أن تحفز الدول البازغة التى تحوز فائض مدفوعات - الصين فى مقدمتها - الطلب الداخلى حتى يمكن للدول المتقدمة - الولايات المتحدة على رأسها - تخفيض العجز فى موازينها وديونها العامة، دون تهديد للإنتعاش الاقتصادى (Dervis). سيكون من مصلحة دول الفائض (الصين) أن تتبنى مثل فولن هذه الاستراتيجية ولكن على دول العجز (أمريكا) أن تحل مشكلاتها الاقتصادية الداخلية كذلك. لن يؤدى الضغط على الثركاء التجاريين (مثل الصين والمكسيك) سوى إلى تحول الاختلال وانتقاله

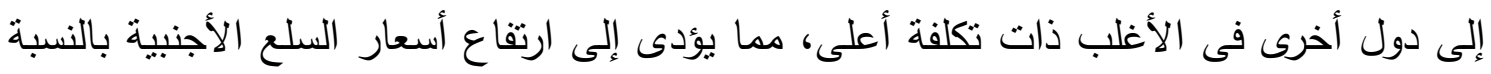
للمستهلكين الأمريكيين (Roach). ينظر الكثيرون إلى العجز التجارى الأمريكى بإعتباره مشكلة

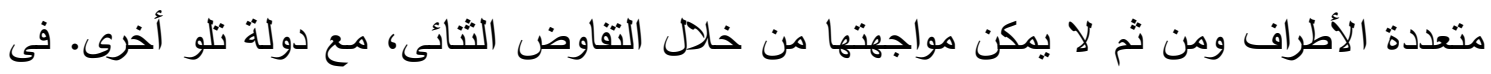

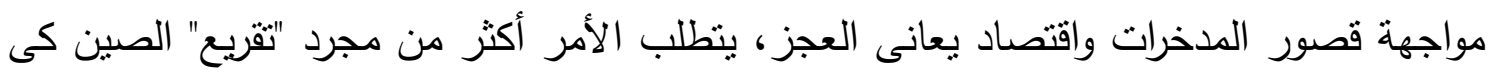

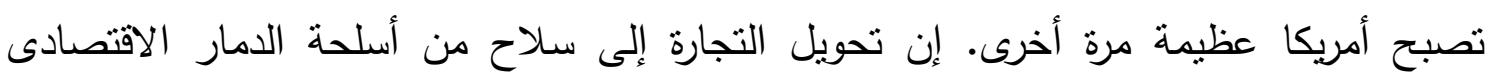
الثامل، يمكن أن يكون مثالاً للتخبط السياسي (Roach).

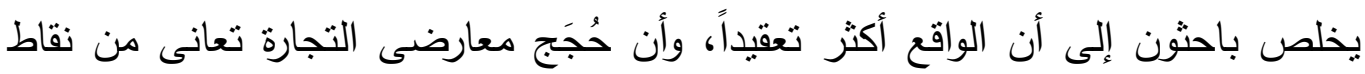

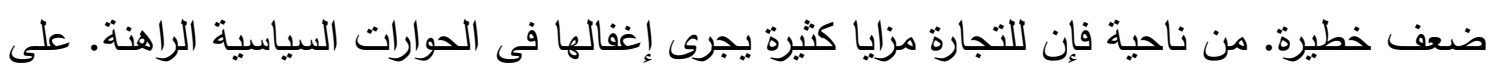
سبيل المثال فان القوة الشرائية للأمريكيين (خاصة أصحاب الدخول المنخفضة) كانت ستصبح أضعف كثيراً بدون الواردات. ومن ناحية أخرى فإن تحدى التشغيل (العمالة) الناجم عن المنافسة

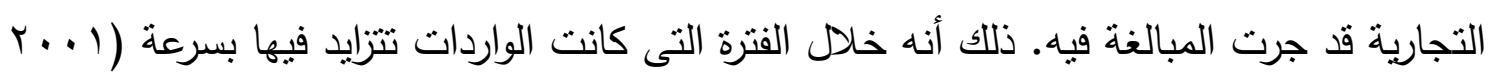

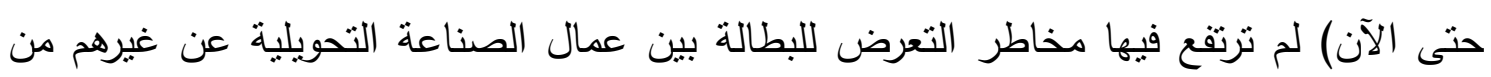
العاملين فى القطاعات الأخرى (Rothwell). وكما يثير الكاتب فإن إحدى الدراسات تذهب إنب إلى أن

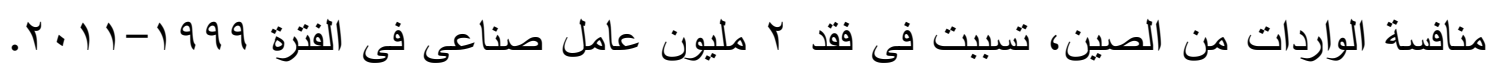
الحقيقة أنه لن تكون ثمة مشكلة إذا صاحب هذا الانخفاض انتقال العمالة إلى قطاعات أخرى. 
فهناك دلائل متعددة على أن العمال الذين فقدوا العمل فى الصناعة وجدوا فرصاً فى قطاعات

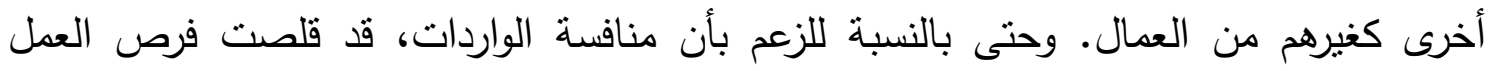

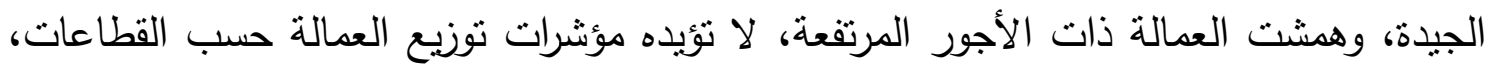
الذى مال إلى التحول نحو القطاعات والوظائف ذات الأجور الأعلى. ويخلص إلى ألى أن العولمة

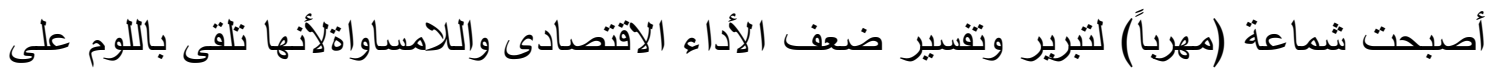

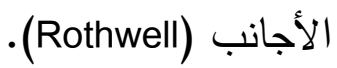

سيشعر المعارضون القدامى بالحيرة عند رؤية الدول التى تزعمت حركة العولمة بقيادة

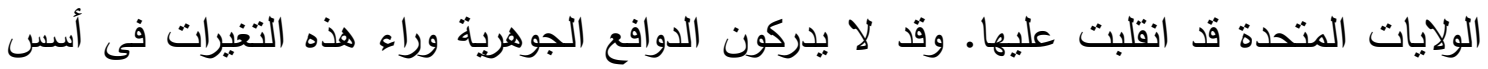

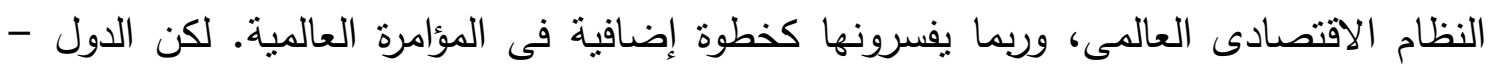
وعلى رأسها الصين - التى قبلت التحدى واغتتمت الفرص تقف اليوم وهى متمسكة بالفرصة، ولفه وتملك الكثير من عناصر القوة للافاع عن حرية التجارة وعن مكانتها فى الاقتصاد العالمى.

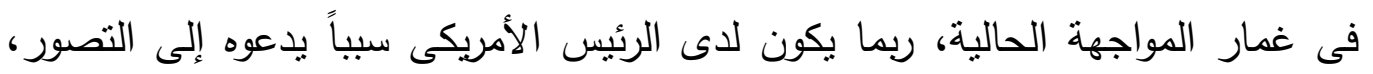

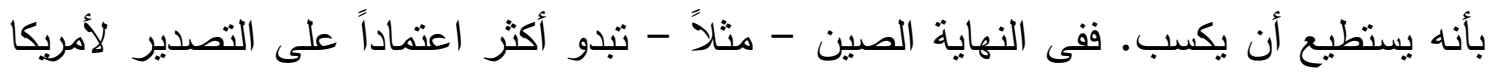

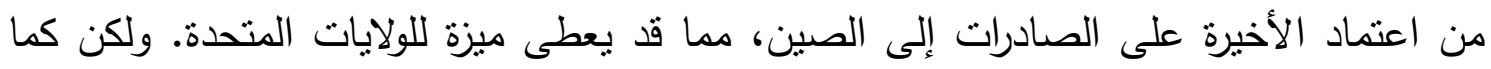
يثير بروفيسور Stiglitz " الحرب التجارية ليست مباراة صفرية ". إذ من الممكن أن تخسر الولايات المتحدة أيضاً. بل ربما تكون الصين فى وضع أفضل للرد على المحاولات الأمريكية لإيذائها. وكما يؤكد يستطيع أى شخص أن يخمن من يمكنه تحمل الألم أكثر من غيره: هل هى الولايات

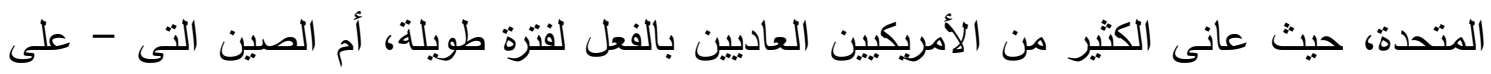
الرغم من الأوقات الصعبة - استطاعت أن تحقق معدلات نمو تفوق V \% ؟ (Stiglitz).

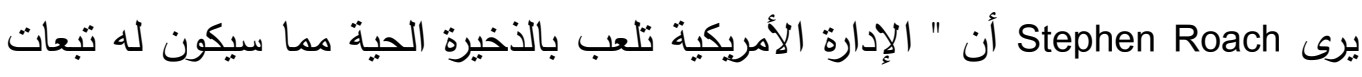
عالمية، وليس هناك أوضح من رد فعل الصين لمحاولة فرد العضلات الأمريكية"، كما يقول إن أمريكا والصين محبوسان فى علاقة اقتصادية منبادلة. صحيح أن الصين تعتمد على الطلب رلب 
الأمريكى على صادراتها، ولكن أمربكا تعتمد أيضاً على الصين التى تملك حوالى 1. دولار فى صورة سندات الخزانة الأمريكية وأصول أخرى. الأكثر من هذا، أن الصين تمثن ثنالث أكبر سوق للصادرات (بعد كندا والمكسيك). من قصر النظر افتراض أن أمربكا تحوز كافة الأوراق فى هذه العلاقة الاقتصادية الثنائية (Roach). الواضح أن الحالة الأبرز فى المواجهة التجارية هى تهديدات ترامب للصين، وأن كثثرين يرون أن الحرب التجارية ستلحق الضرر بكلا الطرفين. ولكن هناك ما يبرر الاعتقاد بأن أمريكا لايها الكثير مما يمكن أن تخسره. وتتضمن عدة مقالات قائمة إجراءات بؤسنع الصين أن تتخذها إذا قرر الرئيس الأمريكى بدء حرب تجارية. إذا تحولت الصين مثناً من طائرات البوينج إلى إلى إيرباص ستفقد أمريكا أكثر من V9 ألف وظيفة. وينصح البعض بأنه بدلاً من اتهام الصين

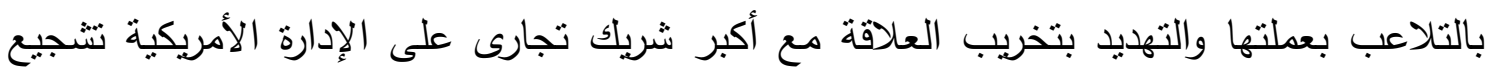
قوى السوق لإعادة توازن تجارتها الثنائية مع الصين (keyu). إن تبعات تتفيذ أمريكا لتهديداتها ضد الصين توادين تتجاوز المدى القصير • فهناك من يعتقد أنه

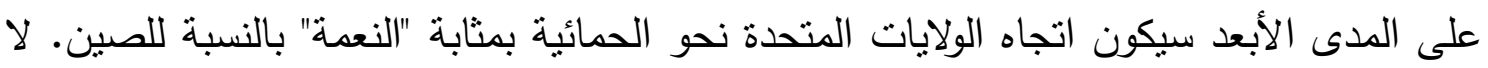
شك أن الصعوبات التى تواجهها الصين (المديونية - تراجع التصدير - والنمو) قد يكون مستغرباً فى ظلاها القول باتجاه الصين إلى مستوى أعلى فى التأثير العالمى، ولكن بسبب سياسة السيد ترامب قد يصبح أمام الصين فرصة ذهبية لحدوث ذلك. لننظر إلى انسحاب أمريكا من الثراكة الباسيفيكية، وهى أكبر اتفاق تجارى إقليمى، الذى سيسحب البساط من تحت أقدام بعض أعضائه مثل ماليزيا وفيتنام وغيرهما، ومن ثم يمنح الصين الفرصة لمساعدتهم. لقد زادت الصين بالفعل استثماراتها الإقليمية من خلال مبادرة "حزام واحد، طريق واحد"، ومن المتوقع كذلك أن تحتل الصين مكانة أمريكا كأكبر مصدر للاستثمارات الأجنبية المباشرة (Basu).

للى أنصار العولمة الكثثير مما يمكنهم سَوْقَهَه للافاع عنها. السياسات التجارية الجديدة، يجب أن تستتد إلى رؤية بعين بصيرة لكيف تطورت العولمة وتتطور باستمرار، وليس بالنظر إلى لئ 


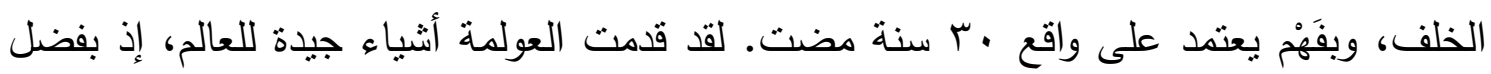

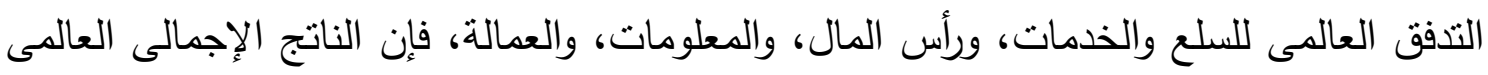

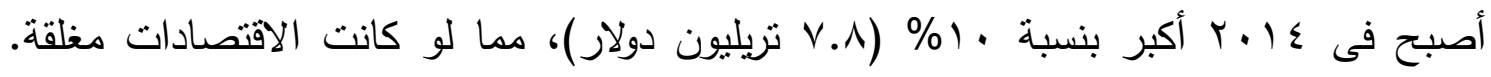

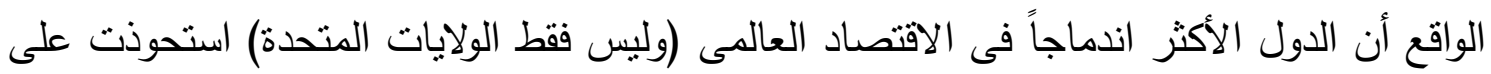

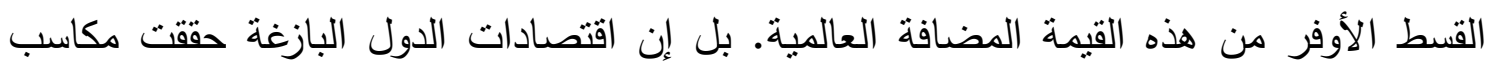

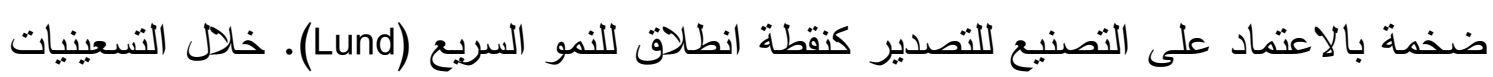

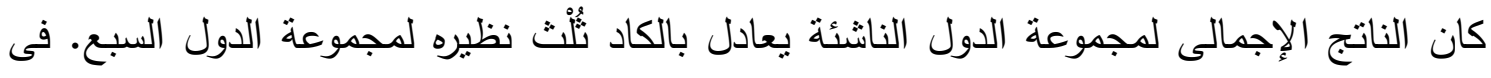

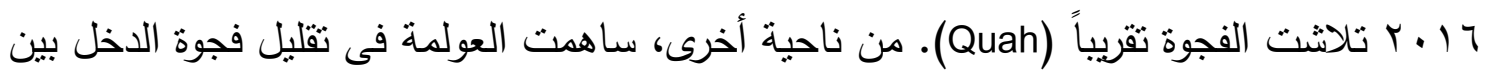

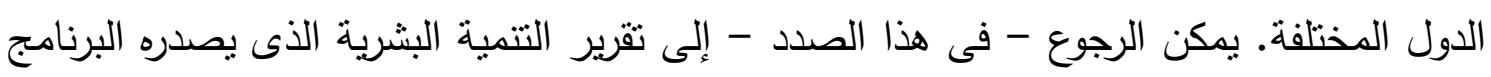

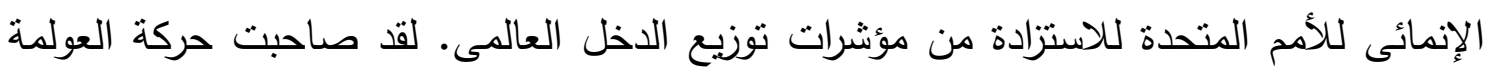

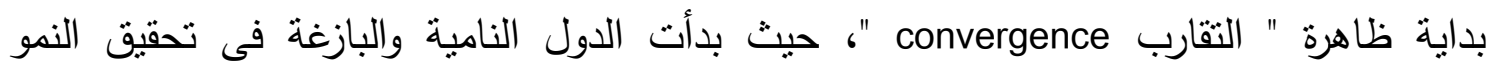

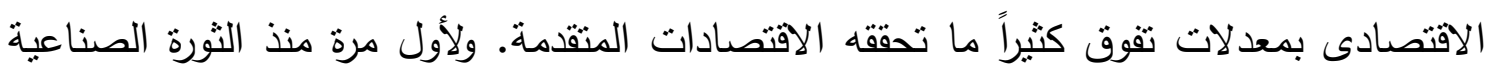

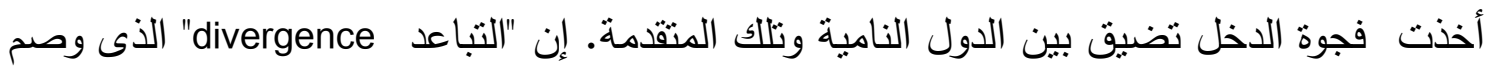

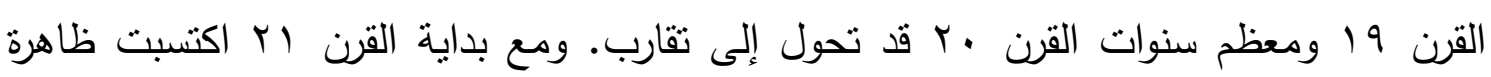

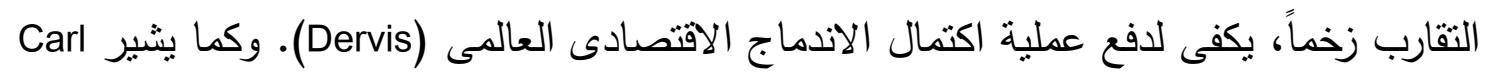

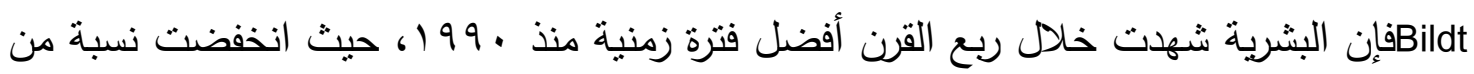

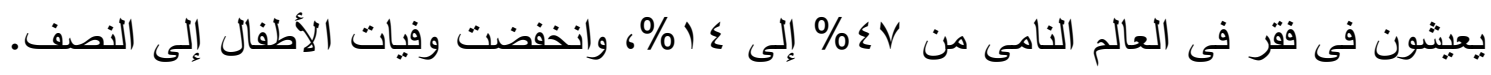

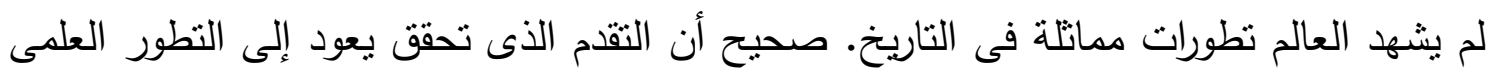

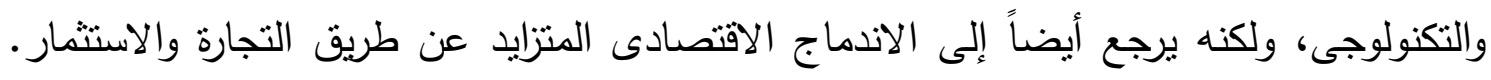

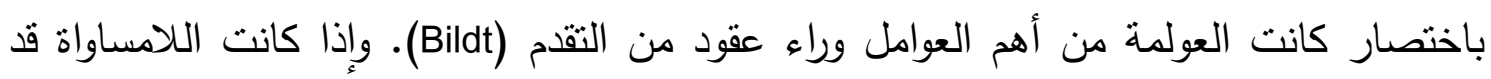

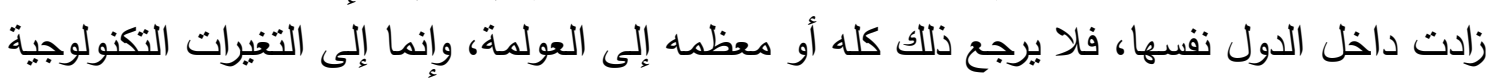

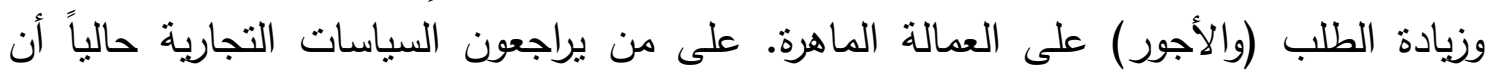

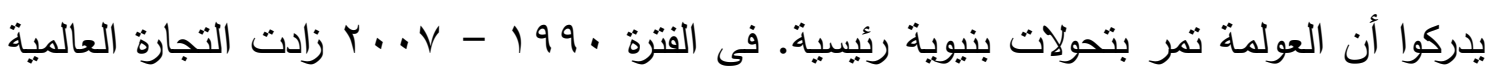

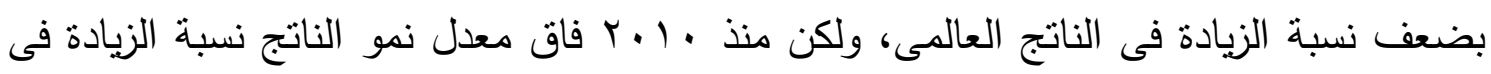


التجارة. لقد أصبح تباطؤ التجارة العالمية هو النمط المتوقع حين تصير العولمة ظاهرة رقمي .(Lund) digital

ربما يكون الثعبويون الأمريكيون قد تأثروا بكتابات Piketty ولم يتفاعلوا مع حقيقة أن

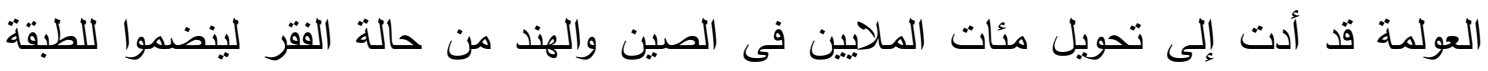

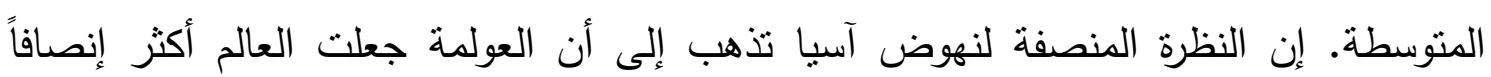
وعدالة، ولم يعد المصير الاقتصادى للمره معتمداً على مكان معيشته أو ولادته (Rogoff).

هل تكفى الحجج والأسانيد التى يقدمها أنصار العولمة على النحو الذى عرضناه فيما نقدم

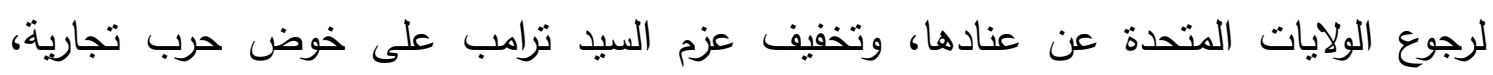

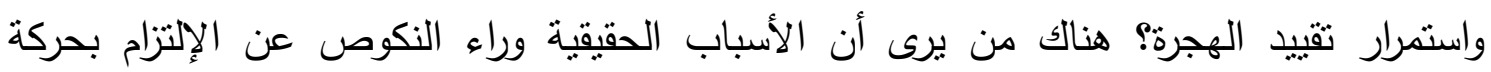

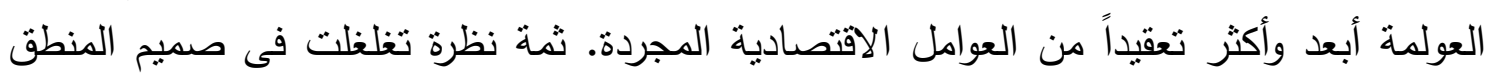

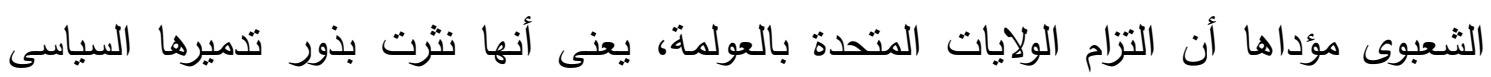

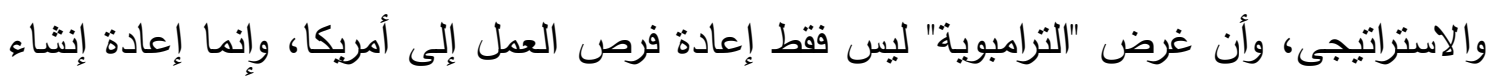

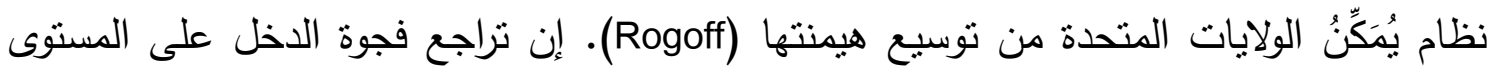

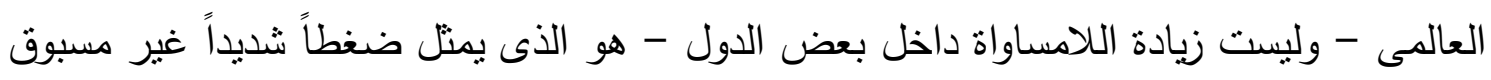

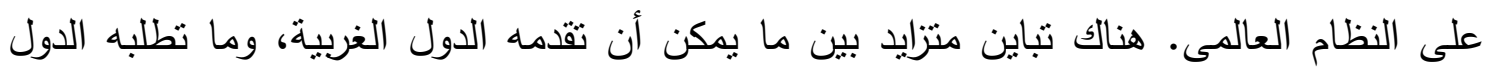

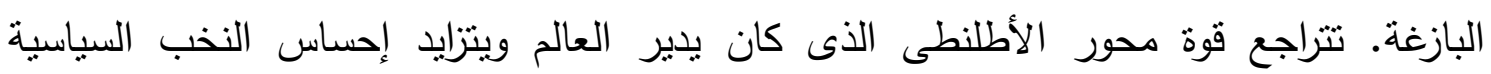

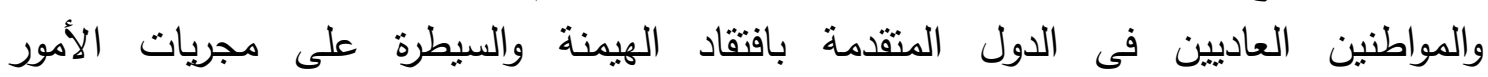
(Economist)

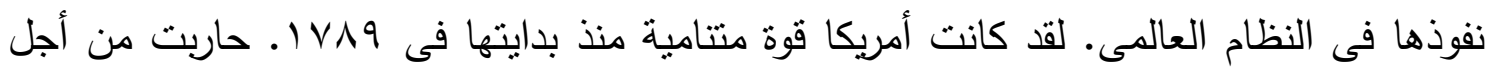

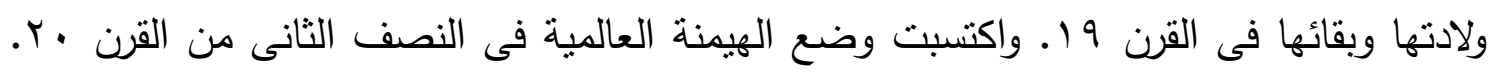

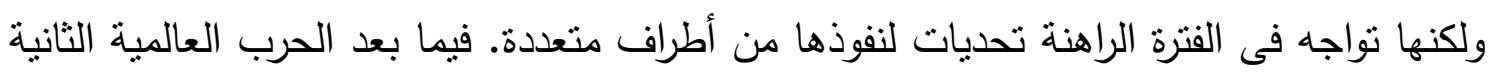

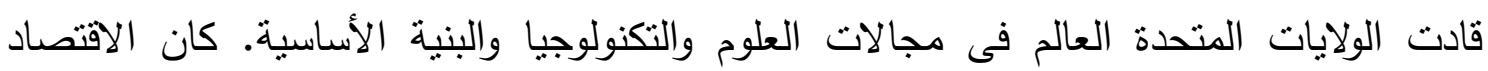
it 
الأمريكى يمثل • بـ\% من الاقتصاد العالمى ويحتل مكانة السبق فى كل القطاعات كثيفة المهارة.

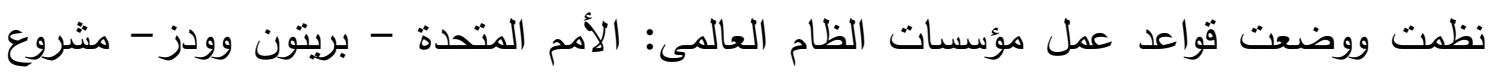

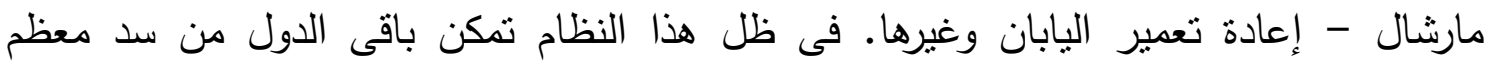

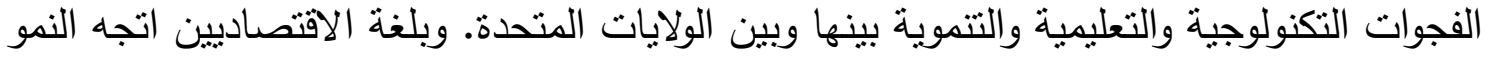

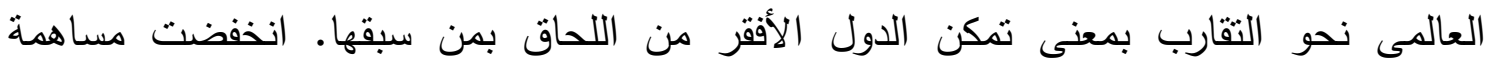

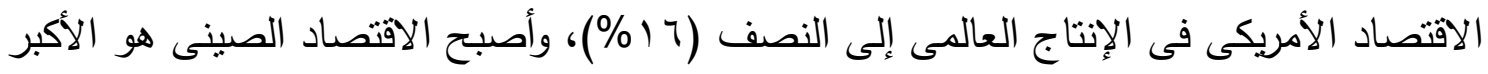

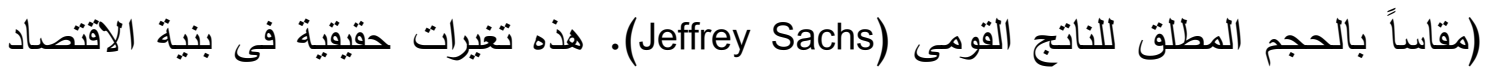
العالمى، تتطلب وصول النظام العالمى إلى نقطة توازن جديدة. ولكن - كما يرى Sachs عندما تسيطر فكرة الهيمنة على رؤية القادة تبدو نتائج التقارب واللحاق بمثابة تهايد للنفوذ الاستراتيجى.

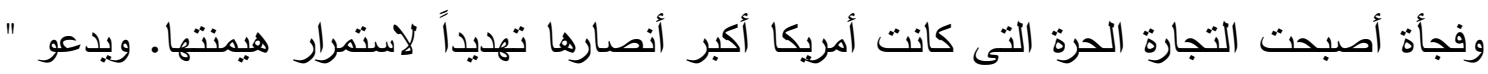

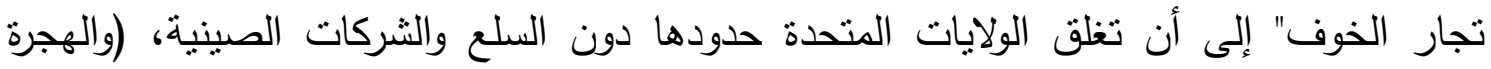

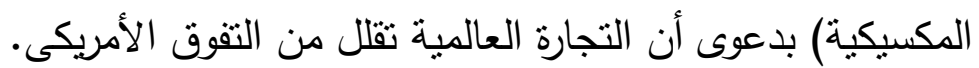

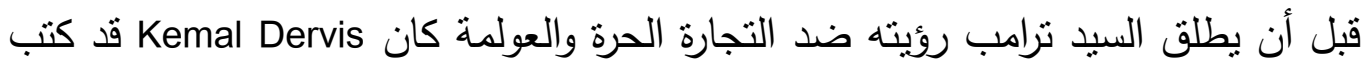
"العولمة هنا لتنقى". ولكنه نساعل عما إذا كانت قادرة على استمرار متوسطات دخل الفرد فى الدول

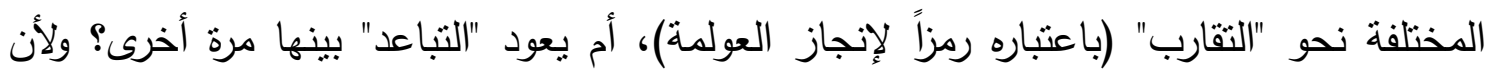

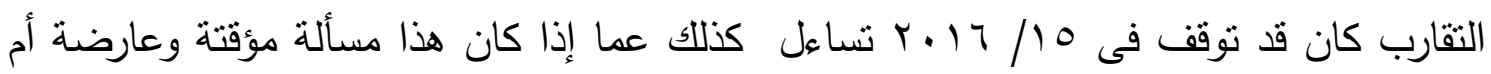

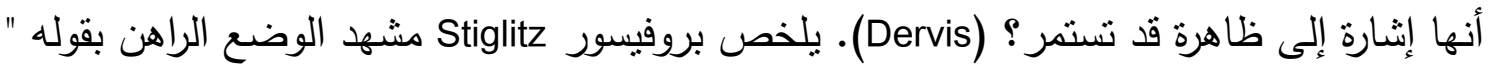

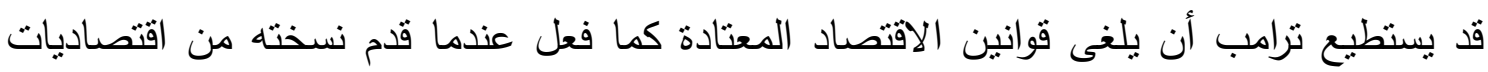

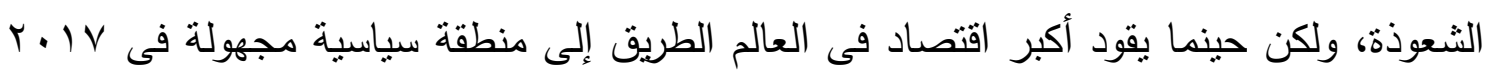

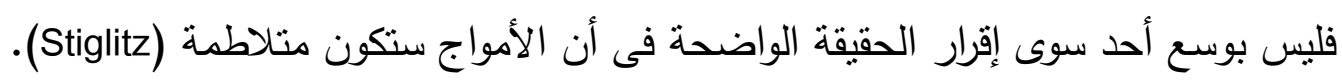
المصادر

- Alshin Molavi, Trump cannot shield America, The Washington Post: January 10, 2017

- Carl Bildt, Restoring Faith in Globalization, Peoject Syndicate: Feb 16, 2017 
عثمان محمد عثمان

- Damian Paletta and Ana Swanson, Trump may ignore WTO, Chicago Tribune: March 21,2017

- Danny Quah and Kishore Mahbubani, The Geopolitics of Populism, PS: Dec 9, 2016

- Jeffrey Kucik, and Rajan Menon, What Trump Gets Wrong, Foreign Affairs: March 8, 2017

- Jeffrey Sachs, Learning to Love a Multipolar World, World Affairs, Dec 29, 2016

- Jonathan Rothwell, Globalization: Scapegoat for Economic Problems, Gallup, Feb 27, 2017

- Jozif Stiglitz, Trumpian Uncertainty, (PS): January 9, 2017

- Kanshik Basu, America's Dangerous Neo-Protectionism, Business \& Finance, Feb 13, 2017

- Kemal Dervis, Reflections on Progress, Essays on the Global Political Economy, Brookings Institution Press, 2016

- Kenneth Rogoff, Why Trump cannot Bully China, PS: Feb 9, 2017

- Keyu Jin and Others, Trump's Economic Labyrinth, PS: Mar 10, 2017

- Politico, Marine Le Pen makes globalization the enemy, March 10, 2017

- Post 2016 World Order, Feb 3, 2017

- Stephen Roach, Trump's Gathering Trade War, SP: Dec.26, 2016

- Susan Lund, Adapting to the New Globalization, PS: Feb 8, 2017

- The Age of Trump, PS: January 10, 2017

- The Economist, The Trump Era, Nov 12, 2016

- Trump's Gift to China, Business \& Finance, March9, 2017. 